\title{
Factive and Fictive in a Literary Critical Text
}

\author{
Lilit Gharagozyan \\ Yerevan State University
}

\begin{abstract}
The aim of the present research is to reveal different stylistic devices that impart expressiveness as well as emotionality to the literary critical text. Being a historical category, scientific style is first of all based on the development of the scientific thought and is characterized by the state of the national language and by the abilities and skills of the author, as well as that of the reader, for whom the scientific text is meant. Scientific prose requires the use of a specific discourse, sometimes with a certain amount of ambiguity and indefiniteness. In recent years, there has been a significant rise in studies concerning the usage of different stylistic devices in scientific discourse, which is a direct indication of a complex dialectical relationship of the two main functional styles. All these elements of emotionality are necessary elements for the literary critical text. They essentially serve as additional reinforcements for the final clarification of the thought which is expressed in a neutral way. It should be noted that the fictive elements play a significant role in scientific discourse, thus contributing to the clarification of scientific theories and principles.
\end{abstract}

Key words: stylistic devices, expressiveness, scientific discourse, literary critical text, metasemiotic level.

\section{Introduction}

A man's style is as specific as his fingerprints. Stylistic analysis can in fact settle many complicated problems in writing style. A writer's use of language, if studied carefully, can reveal his deep-laid philosophy, his aesthetic personality and worldview. 
When two words emotion and science are mentioned together, many people see an intrinsic contradiction. The distinction between the two, however, is probably more falsified than genuine. As indicated by many linguists, nowadays in linguistics there are considerable changes connected with the problem of relationships between language and thought. Scholars, especially during the last decades, have argued that scientific practice and discourse have not only factive but also fictive elements. The authors of scientific papers must demonstrate the validity and objectivity of their findings and make them seem interesting and relevant to already-established conclusions, that is why in recent years there was a gradual rise of interest to stylistic devices used in scientific discourse (Gasparyan 2006).

The elements of emotionality are necessary for scientific texts. They essentially serve as additional reinforcements for the final clarification of the thought, which is expressed in a neutral way. This can be explained, first and foremost, by the common interest to the examination of the texts (the peculiarities of the functional styles), by the tendency to give linguistic substantiation and interpretation to different stylistic devices, which impart expressiveness to the text.

\section{The Functional Specificity of Scientific Texts}

It is already a well known fact that nearly in all kinds of texts we can find different stylistic devices that give emotionality as well as expressiveness to the text.

The fact that we, humans, are not only rational, but also emotional beings has also been illustrated. Thus, our mind and its linguistic manifestations depend on specific circumstances (Gasparyan 2006).

Accordingly, scientific writing provides us with straightforward logical information, while creative writing impresses us. In the course of history, these two polar functions were expressed differently; fiction - nonfiction, factive/real - fictive/unreal(Razinkina 1965).

While approving the opposition of these two functions, we can see that there are infinite types and genres, and it is often very difficult to define the 
boundary between the basic dichotomy of literal and non-literal speech. This is one of the reasons why the questions of perception, understanding and interpretation of texts have long been in the centre of attention of philologists.

It is well known that language means, used in scientific discourse, tend to be objective, precise and unemotional. Scientific prose exists for quite a long time and being a historical category, it is first of all based on the development of scientific thought in a particular country, and is characterized by the state of the national language and the abilities and skills of the author and of the reader for whom the scientific text is meant (Akmanova 1977). The vocabulary of scientific texts has also received a lot of attention. It has been established, for instance, that ready-made, clichéd word-combinations should be taken as a characteristic feature of this register (Gasparyan 2006).

As a result the use of any expressive means and stylistic devices in scientific discourse can lead to the change of the meaning and of the structure of scientific texts. However, although the rigor typical of science requires the use of a specific discourse, a certain amount of fictiveness and ambiguity can also be present. Thus, the use of figurative language helps to overcome the strict limits of scientific harshness, objectivity, and represents ideas and theories in a different, more creative way. That is why, this duality - the factive and fictive nature - of the language of intellective prose is the focus of the present article.

\section{The Elements of Fictive in Factive Texts}

We know that a literary critical text as such, is considered to be an intellective prose. It has a middle position between a scientific text and that of literary one. Thus, as we have already stated above, the usage of fictive elements in any kind of factive text is more than possible, so in order to prove this, let us examine some examples taken from two different literary critical texts.

The first example is taken from Hamlet and His Problem by Eliot. Starting from the very first pages of his criticism, T.S. Eliot somehow summarizes some of Hamlet's already excising literary critical views, and while doing that, consciously or subconsciously he makes use of a stylistic device which is irony ${ }^{1}$ 
"These minds often find in Hamlet a vicarious existence for their own artistic realization. Such a mind had Goethe, who made of Hamlet a Werther; and such had Coleridge, who made of Hamlet a Coleridge; and probably neither of these men in writing about Hamlet remembered that his first business was to study a work of art. The kind of criticism that Goethe and Coleridge produced, in writing of Hamlet, is the most misleading kind possible. For they both possessed unquestionable critical insight, and both make their critical aberrations the more plausible by the substitution - of their own Hamlet for Shakespeare's which their creative gift effects. We should be thankful that Walter Pater did not fix his attention on this play".

(Eliot 1921:55)

Here, by observing the passage, we can see that Eliot tries to look extraordinary or express his attitude towards the subject he has chosen to speak about. He wants to show his reader that he is well-read and has a good background of all the literary critical texts that were written about Hamlet. Our first example is tinged with irony by which Eliot tries to show that he does not agree with some of the critic's ideas. He thinks it is really good and even "we should be thankful"that Walter Pater ${ }^{2}$ did not write anything about Hamlet, as according to Eliot, it would be a failure and he would definitely criticize him as well.

\section{"So far from being Shakespeare's masterpiece, the play is most certainly an artistic failure. In several ways the play is puzzling, and disquieting as is none of the others".}

(Eliot 1921:57)

In the second example we can find a use of antithesis ${ }^{3}$; in the first part of the sentence the critic considers the play to be a masterpiece but then he says that it is an artistic failure and with this contradiction he somehow gives the puzzling atmosphere of the play. If we go back to the original text, we will see that the 
play, particularly monologues of Hamlet, are filled with hesitation and doubt, hence, these parts have their effect on the critic. Generally the impact of the original play is present in every passage of the critical text. E.g.:

"To be, or not to be? That is the question -

Whether 'tis nobler in the mind to suffer

The slings and arrows of outrageous fortune,

Or to take arms against a sea of troubles, And, by opposing, end them? To die, to sleep".

(Hamlet: Act 3, Scene 1)

As can be seen, the above-adduced example is one of the most famous passages of Hamlet, which by influencing Eliot, also influences his language of criticism.

The next example is taken from Lewis's Hamlet: The Prince or the Poem:

"Critic who makes no claim to be a true Shakespearian scholar and who has been honoured by an invitation to speak about Shakespeare to such an audience as this, feels rather like a child brought in at dessert to recite his piece before the grown-ups".

(Lewis 1969:88)

In the above example we see that the critic refuses to use strict scientific prose style, and prefers to play with words, hence, giving a humorous tone to the passage. The use of metaphorical simile ${ }^{4}$ is of particular interest. He compares himself to a child who is unskilled and has a lot to learn. With the help of this simile, Lewis both makes his audience understand that whatever he will say is not an easy task, and that it is a great honor and responsibility for him to speak about Shakespeare and his plays. That is why, as we will see in the next example, he promises to be as honest as a child and "bestow all" his "childishness upon"those people who are listening to him in order not to "deceive" anyone: 
"I should not deceive you: I should not even deceive myself. I have therefore decided to bestow all my childishness upon you".

(Lewis 1969:88)

At the end of his work, however, with the help of a metaphoric construction, Lewis emphasizes that he is not "a sort of literary Peter Pan who does not grow up" and he thinks that "only those adults who have retained, with whatever additions and enrichments, their first childish response to poetry unimpaired, can be said to have grown up at all."

"You must not think I am setting up as a sort of literary Peter Pan who does not grow up. On the contrary, I claim that only those adults who have retained, with whatever additions and enrichments, their first childish response to poetry unimpaired, can be said to have grown up at all. Mere change is not growth".

(Lewis 1969:105)

It is also important to realize that in the neutral style of scientific literature the individualized style of the author should also be emphasized. While analyzing different scientific materials, we face up to a very interesting characteristic feature of English, i.e. their humorous attitude towards the most serious things. This is mostly achieved with the help of comparisons that play a cognitive role and appear unexpectedly in the sentence as we have already observed in the above examples.

It is worth mentioning once again that in case of literary critical writing we should not forget about the original work which has its direct effect on the critic, hence, on his language of writing.

To clarify this point it would be appropriate to study the following passage:

\section{"We see visions of the flesh dissolving into a dew, of the world like an unweeded garden".}


At first sight it may seem that we have just one more example of the fictive element in a piece of intellective prose which is the following simile: "the flesh dissolving into a dew, of the world like an unweeded garden".

But when we go further and compare it with the original play, we realize that several lines coincide. With the help of horizontal context analysis it becomes clear that while talking about one of Hamlet's monologues, the critic himself is influenced by the Shakespearean work of art, and hence, he goes out of the factive frame of scientific discourse.

Having studied both texts, we come to the conclusion that in some cases we have an allusion ${ }^{5}$ and to some extend a deformation ${ }^{6}$ of the original text in the literary critical work. To make our claim more understandable, we bring the two texts together in Table 1 below to show the similarities between them.

(Table 1)

How weary, stale, flat, and unprofitable Seem to me all the uses of this world! Fie on 't, ah fie! 'Tis an unweeded garden

That grows to seed. Things rank and gross in nature.

Possess it merely. That it should come to this!

But two months dead: nay, not so much, not two:

So excellent a king; that was, to this,

Hyperion to a satyr; so loving to my mother

That he might not beteem the winds of heaven

Visit her face too roughly.

Heaven and earth!

(Hamlet, act 1, sc. 2)
For what, after all, is happening to us when we read any of Hamlet's great speeches?

We see visions of the flesh dissolving into a dew, of the world like an unweeded garden.

(Lewis 1969:99) 
The mirroring of the original play can also be easily seen in the next example, presented in Table 2 below.

"There are ten lines of it before we reach what is necessary to the plot: lines about the melting of flesh into a dew and the divine prohibition of self-slaughter".

(Lewis 1969:98)

(Table 2)

Oh, that this too, too solid flesh would melt,

Thaw, and resolve itself into a dew!

Or that the Everlasting had not fixed

His canon 'gainst self-slaughter! $O$ God, God!

There are ten lines of it before we reach what is necessary to the plot: lines about the melting of flesh into a dew and the divine prohibition of selfslaughter.

(Lewis 1969:99)

(Hamlet, act 1, sc. 2)

Works of literature lead a life of their own and they receive something new from each generation of the readers that comes to them because we look at literature through lenses that are different and multiple. Those lenses are our nationality, age, family background, sex, political, socio-economic status, the century, our mood, and generally our cognition of the world; they all influence the perception of a literary text.

The aim of the present article, as stated earlier, was to reveal different stylistic devices that impart expressiveness as well as emotionality to the literary critical text. Feelings and thus, fictive elements, are very important in literary critical discourse because they help the critic and the reader to appropriate their own experience. Those elements are the ones to help critics not to feel themselves as somebody who has to be only very factive but also to be a human who can also play with the words and show us his worldview. 


\section{Conclusion}

The popular belief of the past century that scientific language is merely a transparent transmitter of natural facts, or that the scientific paper gives only a totally misleading narrative of the processes of thought that goes into the making of scientific discoveries, as we saw with the help of our study, is not always right. We have illustrated that there is a creative side to science, a side often sacrificed to an assumed objectivity. Creativity is more often subjective than objective, and so alternative interpretations exist. As we have observed, the use of expressive-emotional-evaluative elements in a literary critical text is accounted for by the great wish of the writer to sometimes look extraordinary, show his cognition of the world, sometimes express his attitude towards the literary work he has chosen to speak about and his great wish to convince the readers in the righteousness of his approach to the problem. It is notable that the overstepping of the stylistically neutral, informative narration very often appears when the critic tends to clarify his points of view and uses fictive elements to explain something very difficult. This can be accounted for by the fact that we use both hemispheres of our brain simultaneously which has its influence on the language we use, however, we shouldn't forget that though the possibility of finding many stylistic devices in literary critical texts is more than obvious, we can never speak of their linguopoetic function in this case, hence, a literary critical text, largely speaking, can never cross the border of logicality and matter of factness.

\section{Notes:}

1. Irony is a figure of speech in which words are used in such a way that their intended meaning is different from the actual meaning of the words (Gasparyan, Matevosyan 2011:150).

2. Walter Horatio Pater was an English essayist, literary and art critic, and fiction writer, regarded as one of the great stylists. His works on Renaissance subjects were popular but controversial, reflecting his lost belief in Christianity (Wikipedia 2018, Available at: <https://en.wikipedia.org/wiki/Walter_Pater> [Accessed April 2018]). 
3. Antithesis, literal meaning opposite, is a rhetorical device in which two opposite ideas are put together in a sentence to achieve a contrasting effect (Gasparyan, Matevosyan 2011:138).

4. In case of metaphoric simile, the transfer acquires a different character, the one-to-one correspondence of form and content of linguistic units is violated; the comparison is based on inner characteristic features of the objects compared (Gasparyan, 2013).

5. Allusion is a brief and indirect reference to a person, place, thing or idea of historical, cultural, literary or political significance. It does not describe in detail the person or thing to which it refers. It is just a passing comment and the writer expects the reader to possess enough knowledge to spot the allusion and grasp its importance in a text (Gasparyan, Matevosyan 2011:136).

6. The term deformation renders the peculiarities of the processes which take place when an idiom, saying or other combination of words is broken in speech, then the refashioned as the case maybe (Gasparyan, Matevosyan 2011:136).

\section{References:}

1. Akhmanova, O. (1977) Linguostylistics: Theory and Method. M.: MUP.

2. Gasparyan, S.K. (2006) The Linguostylistic and Linguopoetic Analyses in Action. Yerevan: Gitelick N 16.

3. Gasparyan, S.K. (2006) On Objectivity in Understanding Verbal Art. // The Knowledge of Literature. Vol. V. Bergamo: Bergamo University Press.

4. Gasparian, S.K.; Matevosian, A.I. (2011) English Style in Action. Yerevan: Lusakn.

5. Razinkina, N.M. (1965) Elementy emotsional'no-subektivnoy otsenki v stile angliyskoy nauchnoy prozy. M.: MGU.

6. Wikipedia (2018) Available at: <https://en.wikipedia.org/wiki/Walter_Pater> [Accessed April 2018]. 


\section{Sources of Data:}

1. Eliot, T.S. (1921) Hamlet and His Problems. // The Sacred Wood and Major Early Essays. New York: Mineola, Dover Publications.

2. Lewis, C.S. (1969) Hamlet: The Prince or the Poem. // Selected Literary Essays. Cambridge: CUP.

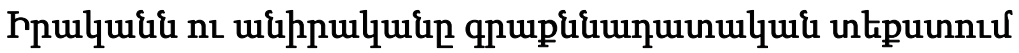

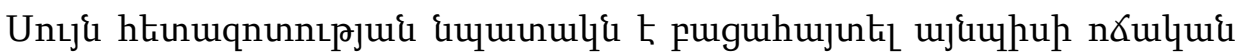

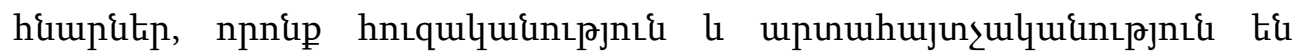

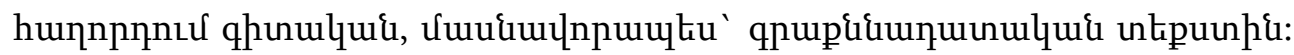

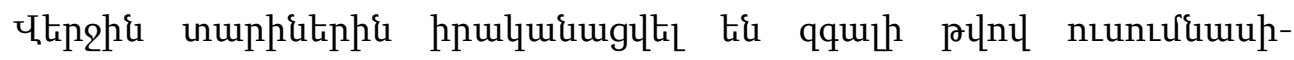

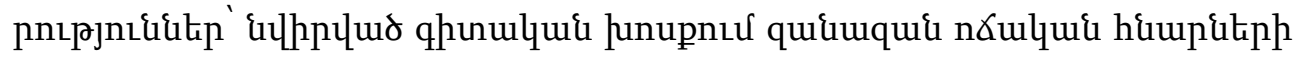

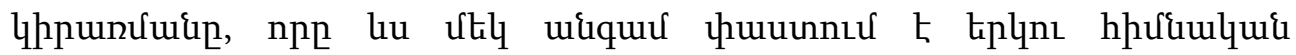

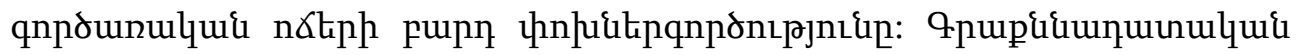

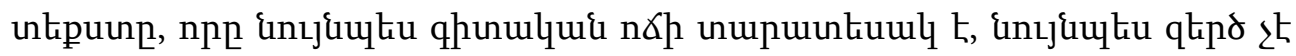

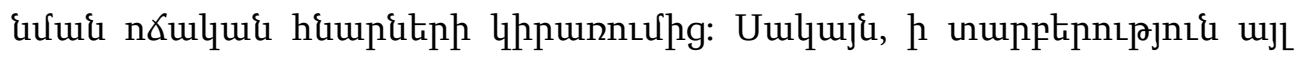

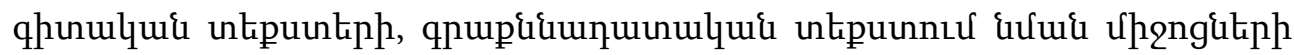

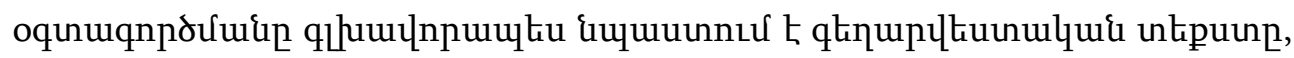

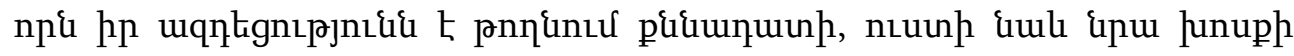
ไnu:

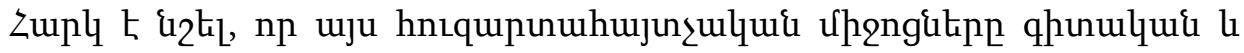

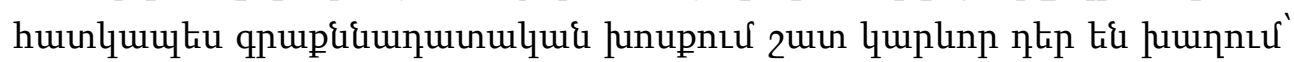

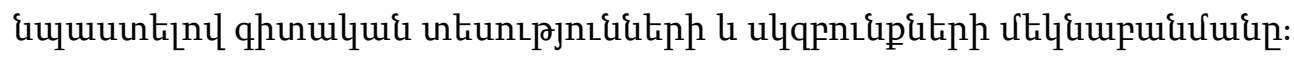

